\title{
Internet in Modern Russia: History of Development, Place and Role
}

\author{
Alexander Galushkin ${ }^{1,2}$ \\ ${ }^{1}$ Department of Humanitarian, Social, Economic and Information-Legal Disciplines, International Institute of \\ Informatization and Public Administration named in the honor of P.A. Stolypin, Moscow Region, Russian \\ Federation \\ ${ }^{2}$ Department of Municipal Law, Peoples' Friendship University of Russia, Moscow, Russian Federation \\ Correspondence: Alexander Galushkin, Department of Humanitarian, Social, Economic and Information-Legal \\ Disciplines, International Institute of Informatization and Public Administration named in the honor of P.A. \\ Stolypin, Moscow Region, Russian Federation. E-mail: Alexander.Galushkin@yandex.ru
}

\author{
Received: March 15, 2015 Accepted: April 23, 2015 Online Published: June 5, 2015 \\ doi:10.5539/ass.v11n18p305 URL: http://dx.doi.org/10.5539/ass.v11n18p305
}

\begin{abstract}
In the present article author analyzes theoretical and practical questions of the role and place of Internet in modern Russia. Author also presents a short history of the Internet development in Russia and states reasons for non-existence of the Internet in the Union of Soviet Socialist Republics (USSR) and its development in the end of the Soviet Union history and start of the modern Russian country history. Author discuses question of Internet use in modern Russia and reasons for the widespread of information technologies and especially Internet, analize questions of the information security in the condition of globalization and spread of information technologies. During the discussion authors use statistical data and present opinions of different specialists. In the conclusion author points out that in the modern world information technology may be dangerous, and not only may it be dangerous for individuals but it may pose threat directly to government and society in general, appropriate legal regulation and law-enforcement is required.
\end{abstract}

Keywords: communication, history, information, Internet, perspective practice, Russia, security

\section{Introduction}

Information technology became a part and parcel of most people's daily lives all over the globe. Russia is not an exception with different kinds of information technology being actively used by people, organizations, businesses, institutions, public associations, as well as governmental and municipal authorities.

Geographic distribution of information and telecommunication networks in the Soviet Union didn't pick up the pace until 1990. The Relcom network was the first Soviet and Russian computer network. It was launched in August 1990 in the Kurchatov Institute of Atomic Energy in Moscow by connecting voice band modems (for sending e-mails using the UUCP protocol) in scientific institutions of Moscow, Leningrad and Novosibirsk. The network was launched in collaboration with the Demos programming cooperative, which shortly afterwards became the first Russian Internet service provider.

The first connection to the global Internet was a dial-up connection from Moscow to Helsinki University on August 28, 1990. On September 19 of the same year Relcom and Demos registered the country's top-level domain - .su, which laid the foundation for systematic information exchange (mainly through the Usenet discussion system). That encouraged more Soviet cities to join the network (The Annual Report, 2014).

In the last 25 years our country has leapt forward in its joining the global information space, despite the complexity of information and telecommunication technology development in the USSR, RSFSR and Russia. The fall of the Iron Curtain facilitated the improvement of connection methods and the development of new, more advanced technologies of data transmission. Information technology has made a major breakthrough in a fairly short period of time due to new cutting-edge receivers and transmitters, and more accurate and advanced software. Moreover, the hardware has become more compact and portable with a few different functions.

The development of information technology was also largely driven by the massive expansion of the Internet global network. "The first 12 years of the $21^{\text {st }}$ century were notable for revolutionary changes caused by the extremely rapid growth of information and telecommunication technology (ICT) and above all the Internet" 
(Baseley, Bommelaer, Vasilyev, Weber, Bommelaer, Kummer, Orlov, Ponder, Reed, \& Yakushev, 2013, p. 185-206).

In 1993 the Internet global information and telecommunication system was only used by 0.25 per cent of the population. In 1997 the number of users reached 100,000 people, in $2001-500,000$ people, in 2005 it grew up to one billion, in 2010 it doubled reaching two billion, and in 2014 the number of users amounted to 2,925,249,355 people, which equals to 40.4 per cent of the world's population.

\section{Discussion}

"Today we can say that the Internet covers all countries in the world because modern technologies (mobile satellite services) have made it possible to connect to the Internet from any part of the globe. As for the infrastructure, the Internet is available in over 150 countries" (Chesnokov, 2013, p. 14). It is worth mentioning that throughout the period of 21 years (1993-2014) the percentage of Internet users increased by 161,52 times, with allowance for the population growth.

The process of Internet expansion is different and not geographically even - a lot depends on the population size and density, per capita income, the median age, education level, and how developed the information and telecommunication structure in the region is. 48.4 per cent of the users today are located in Asia, 21.8 percent in North and South America, 19 per cent are in Europe, 9.8 per cent - in Africa, and 0.6 per cent are located in Oceania.

There are 195 independent countries in the world today (Volkova, 2013, p. 4), 193 of which are UN members, and the remaining 2 are observers. However, as of December 2013, over 66 per cent of the population was located in only 20 countries: China, USA, India, Brazil, Japan, Russia, Germany, Nigeria, Great Britain, France, Indonesia, Mexico, Iran, Philippines, Egypt, South Korea, Vietnam, Turkey, Italy and Spain.

Obviously these countries boast the largest numbers of Internet users - nearly 74 per cent of the population, and in some of the states these figures are even bigger: 1) Great Britain - 89.8 per cent, 2) Japan - 86.2 per cent, 3 ) Germany - 86.2 per cent, 4) South Korea - 84.8 per cent, 5) USA - 84.2 per cent, 6) France - 83.3 per cent.

It is important to mention that 4 developing countries out of the 20 states mentioned above, saw the phenomenal growth in the number of Internet users in the period between 2000 and 2013: 1) Nigeria - 33,559.6 per cent, 2) Vietnam - 20,406.1 per cent, 3) Iran - 17,900 per cent, 4) Egypt - 9,470 per cent. The lowest growth rate throughout the same period of time took place in the 6 most technologically and economically advanced countries: 1) South Korea - 118.3 per cent, 2) Japan - 132.9 per cent, 3) Italy - 173.2 per cent, 4) USA - 181.6 per cent 5) Germany - 190.7 per cent 6) Great Britain - 271.9 per cent.

It is interesting that the growth in the given 20 countries between 2000 and 2013 amounted to 658.2 per cent, in the rest of the countries it was 732.9 per cent, and in the whole world in total it reached 676.3 per cent. These figures show that in developed countries the growth rate of Internet users is 74.7 per cent higher than in the 20 countries where the majority of the users reside.

As of December 2013, the number of Internet users in Russia amounted to 87,476,747. Thus, Russia takes the $6^{\text {th }}$ place in the world by the number of Internet users. However, this is only 61.4 per cent of the Russian population, so by the Internet use rate Russia ranks eighth among the 20 states.

As we all know, Russia is the largest country in the world by landmass, which is clearly a deterrent of developing national Internet services. However, it resulted in numerous telecommunications service providers in Russia, which can't be said about many Western countries. For example, as of February 1, 2015 the Register of telecommunications licenses "contains information about 37,775 licenses" (Register of telecommunications licenses, 2015). Today there are 4 main forms of Internet access in Russia: cable, wireless (including mobile Internet), satellite, and dial-up.

\section{To the Question of Internet Resources Growth}

There are objective reasons making it obvious that the number of Internet users will keep growing. People actively use all sorts of information and network resources in the Internet, as well as ability to directly connect with each other. Besides, the information and network resources are numerous, and their number tends to grow continuously. For instance, in April 2014, the number of second-level domains registered under top-level domains (TLD) amounted to 271 million (The Domain Name Industry Brief Volume 11 - Issue 1 - April 2014, 2014), and in December 2014 it went up to 280 million. Thus the number of domain names grew by 9 million within 8 months (The Domain Name Industry Brief Volume 11 - Issue 3 - December 2014, 2014). 
A list of the ten most popular top-level domains (TLD) looks as follows: 1) .com, 2) .tk - Tokelau, 3) .de Germany, 4) .cn - China, 5) .uk - Britain, 7) .org, 8) .ru - Russia, 9) .info, 10) .nl - the Netherlands (The Domain Name Industry Brief Volume 11 - Issue 3 - December 2014, 2014).

Thus the top ten includes 4 generic top-level domains (gTLD) and 6 country code top-level domains (ccTLD): Tokelau, Germany, China, Great Britain, the Netherlands and Russia.

It might seem surprising that the country code top-level domain of Tokelau is second most popular among all top-level domains. It becomes even more surprising when you find out that Tokelau is a territory of New Zealand in the South Pacific Ocean that consists of three tropical coral atolls with a population of 1,337 people (as of July 2014) (Australia-Oceania: Tokelau (territory of New Zealand), 2015).

The reason for such high popularity is explained by the fact that most Internet services in Tokelau are free of charge for both personal and commercial use. This generous, client oriented approach, along with the quality of the services, makes it clear why Tokelau's country code top-level domain boasts such an extraordinary popularity, which in its turn, has a positive influence on the country's image.

The .ru domain is in the top ten of top-level domains (TLD), ranking sixth by the total number of Internet users and ranking fifth among country code top-level domains (ccTLD), which proves that Russia boasts a high Internet use rate. It should be mentioned that this statistics allows for second-level domains registered under top-level domains, but there are 3 country code top-level domains for Russia (.ru, .su, .pф), which is not taken into consideration.

As of December 2014, the number of second-level domains registered under the .ru domain was 4,866,203, under the .p申 domain it was 835,792, and under the .su domain it amounted to 117,291 (Russian domain name market: statistics, history, trends, 2014). The total number is 5,819,286.

Thus, 83.62 per cent of the registered second-level domains fall within the .ru domain, 14.36 per cent - within the .p $\phi$ domain, and only 2.02 per cent fall within the .su domain, making it clear what Russian users prefer.

However, along with top-level and second-level domains there can be third-level domains, fourth-level domains, etc. In view of some peculiarities of the information technology development in Russia after the collapse of the Soviet Union, third-level domains for Russian geographic locations (.msk.ru, .spb.ru, .nov.ru and 77 other third-level domains) were much more popular than second-level domains for a very long time. Until recently those had been managed by "Relcom (an acronym for Reliable Communications) - the first Russian computer network and commercial Internet service provider in the USSR, whose development led to emerging of the Runet" (History of the company Relcom, 2013).

It must be pointed out that the given 'geographic' domains were classified as special-type domains, so "it was forbidden to charge any fees for registration and prolongation of domains in these zones" (The Annual Report, 2014). Thus, ever since the creation of Russian 'geographic' domains and other third-level domains, a lot of Internet users have been registering different information resources under their own free domains.

\section{Domains Registered and Number of Information Resources}

According to the information provided by the Internet Assigned Numbers Authority (IANA) - "a nonprofit organization, which oversees global IP address allocation, creation and management, as well as root zone management" (Kasenova, 2013) - as of January 31, 2015 the register of top-level domains included 809 records (TLDs Alpha By Domain List, 2015), but the information about the exact number of domains registered under all top-level domains managed by Russian users was missing. However, the number is obviously higher than $5,819,286$, although there are a lot of domains that are not used comprehensively and thus can't be classified as autonomous information resources.

According to the Coordination Center for TLD RU, as of December 2014 there were 4,859,458 domain names registered in the .ru top-level zone, only 2,130,429 (43.84 per cent) of which were recognized as websites (Purposes of the .RU domain use, 2014), the .su top-level zone included 117,246 domain names, 39,680 (33.84 per cent) of which were recognized as websites (Purposes of the .SU domain use, 2014), and finally there were 835,181 domain names in the .pp top-level zone, 194,898 (23.34 per cent) of which were recognized as websites (Purposes of the .РФ domain use, 2014). Therefore the total number of domains recognized as websites in all three zones was 2,365,007. The rest fall into one of the following categories: site under construction, undelegated, parked domain, error, site not found, redirected, undefined. In general the number of functioning websites in the .ru, .su and .pф domain zones is relatively low (less than 45 per cent). Most of those websites (43.84 per cent) are in the .ru zone, 33.84 per cent are in the .su zone, and 23.34 per cent fall within the .p $\phi$ zone. 
The rest of the domain names are not used comprehensively (site under construction, parked domain, gives an error, site not found, redirects to a different site or the domain is undelegated at all).

In 2013 the total number of websites all over the world amounted to 672,985,183 while the number of Internet users at that period was $2,756,198,420$. This means that on average there is one functioning website per every four Internet users. At that, despite a decline in the number of websites in 2010 and 2013, the number clearly tends to increase constantly. It is interesting that throughout the first 6 years the number of websites grew exponentially, however compared to the number of websites we have these days, the figures were much smaller. Since 2000 the number of websites has grown systematically by tens of thousands every year. Starting from 2010 their number has grown constantly by around 150,000 websites per year.

Such growth rate of information resources and popularization of the Internet among people all over the world and Russia in particular shows that the use of telecommunications technology becomes more active by the year, and its applications become more diverse.

\section{Reasons for the Internet Use}

According to the Russian Public Opinion Foundation, as of June 27, 2014 "the number of active Internet users those going online at least once a day - was 50 per cent (58.3 million people). The annual growth rate of Internet users that go online once a month was 7 per cent, while the growth rate for those using the Internet once daily was 12 per cent" (Internet in Russia: proliferation trends, Spring 2014).

According to a nationwide survey 'Do you use the Internet? If yes, how often? ' held by Levada Center on June 20-23, 2014 "among 1,600 urban and rural people aged 18 years and over in 134 localities in 46 Russian regions" (Internet. Press releases., 2014), 46 per cent of the population use the Internet daily -26 per cent of them go online a few times a day. As of July 2013 the number of daily users was 6 per cent lower. However, this was due to the increase in activity of regular Internet users who don't go online very often. At the same time in 2014 the number of non-users grew by 1 per cent as compared to 2013, although 8 per cent of the respondents "have access to the Internet". The total number of Internet users amounted to 63 per cent of the population.

On October 13, 2014 the Russian Public Opinion Research Center (WCIOM) introduced the results of a nationwide survey carried out on "October 4-5, 2014. The survey involved 1,600 people in 130 localities in 42 Russian regions". The research center concluded that "the ratio of Internet users in Russia hasn't changed throughout the year and still equals to two thirds of the Russian population (66 per cent), 46 per cent of which go online daily, 19 per cent use the Internet weekly or monthly, and 1 per cent are very rare users" (Press release No. 2692 "Internet: entertainment, communication, work...", 2015). The age groups of the daily Internet users were as follows: 84 per cent - 18-24 years old, 72 per cent - 25-32 years old, 60 per cent - 35-44 years old, 29 per cent - 45-59 years old, 9 per cent - 60 years old and over (Press release No. 2692 "Internet: entertainment, communication, work...", 2015).

As seen from the statistical information provided, the figures fluctuate within about 10 per cent because of the use of different information sources. It is safe to say that around one third of the Russian population doesn't use the Internet for different reasons, and over half of the population is active users. It is important to understand what so many Russians use the Internet for.

According to a nationwide survey 'Do you use the Internet? If yes, for what purposes? (multiple answers are possible) held by Levada Center on June 20-23, 2014 "among 1,600 urban and rural people aged 18 years and over in 134 localities in 46 Russian regions" (Internet. Press releases., 2014) the most popular purpose among the Russian Internet users is "to look up necessary information", "to communicate with others", "for entertainment", "to follow the latest news", "to find/listen to music", "to find/ watch movies", "to find/buy goods or services", "to find out what is happening within the country and abroad", "to find/read books". The number of users in all the categories has increased over the last 4 years.

The "to look up necessary information" category has seen a 7.32 per cent increase in the number of users in 2013-2014, and a 33.33 per cent increase throughout 2011-2014, the "to communicate with others" category has seen a 16.13 per cent increase in 2013-2014, and a 44 per cent increase throughout 2011-2014, the "for entertainment" category has seen a 14.81 per cent increase in 2013-2014, and a 63.16 per cent increase throughout 2011-2014, the "to follow the latest news" category has seen a 11.11 per cent increase in 2013-2014, and a 50 per cent increase throughout 2011-2014, the "to find/listen to music" category has seen a 23.81 per cent increase in 2013-2014, and a 62.5 per cent increase throughout 2011-2014, the "to find/ watch movies" category has seen a 8.33 per cent increase in 2013-2014, and a 52.94 per cent increase throughout 2011-2014, the "to find/buy goods or services" category has seen a 35.71 per cent increase in 2013-2014, and a 72.73 per cent 
increase throughout 2011-2014, the "to find out what is happening within the country and abroad" category has seen a 18.75 per cent increase in 2013-2014, and a 90 per cent increase throughout 2011-2014, the "to find/read books" category has seen a 23.08 per cent increase in 2013-2014, and a 100 per cent increase throughout 2011-2014. As we can see, some of the categories have shown phenomenal growth rates (up to 100 per cent). However, the author of the paper thinks that a lot of the categories are quite vague and inaccurate, which doesn't allow us to analyze some other purposes of the Internet use.

As a comparison, according to a nationwide survey carried out by the Russian Public Opinion Research Center (WCIOM) on "October 4-5, 2014 that involved 1,600 people in 130 localities in 42 Russian regions", the main purpose of the Russian Internet users is "to catch up with the latest news within the country and abroad (82 per cent of the users, 34 per cent of which use the Internet for this purpose daily), and to broaden their mind (81 per cent).

Different media resources portals with music, movies and books are in very high demand, too ( 80 per cent). Three quarters of the Russian population (77 per cent) use electronic mail (which is a daily routine for 37 per cent), 74 per cent use social networks to communicate with their friends, and only 54 per cent go online to find new friends; 70 per cent of the respondents use the Internet for their studies or work every now and then, while the number of daily users in this category is only 37 per cent (adult professionals -52 per cent, 18-24 year-olds 46 per cent).

Online games are attractive to 54 per cent of the Internet users, while 43 per cent are indifferent to them. Less than half of the respondents ( 43 per cent) do online shopping, and 54 per cent of the users never use this service at all. Software updates are downloaded by 40 per cent of the respondents ( 15 per cent - once in a few weeks/months, 16 per cent - less often). Around 20 per cent of the users confessed they visited porn sites. And, finally, the least popular Internet activity according to the survey is blog writing - only 14 per cent of bloggers among the respondents" (The Annual Report, 2014).

\section{Conclusion}

Today "the Internet is clearly a one-of-a-kind space that comprises both an information exchange network and a platform for all sorts of business activities. ... A lot of the social life areas become virtual - the relationships take place in the so-called null space" (Bachilo, 2000).

Information technology has become part and parcel of many people's daily lives to such an extent that a lot of activities are now either fully carried out online, or done with help of the Internet.

The Internet in Russia today is used not just for communication or entertainment, but also for carrying out business and banking operations, commercial and social activities, providing government services, ensuring public access to court records and mass media activity, and many other things including scientific and educational purposes. Moreover, given the unique features of the Internet network, a lot of activities can be carried out from nearly any part of the world, and the Internet proliferation creates a lot of jobs.

However, in the modern world information technology can be dangerous, and not only can it be dangerous for individuals but it can pose a threat directly to governments and the society in general. As a result of its across-the-board use, information technology has undergone some changes, and so has the modern warfare means and military tactics - some of the approaches now even allow for information security vulnerability (Korsakov, 2012), which can be called cyber wars and cyber espionage (Baseley, Bommelaer, Vasilyev, Weber, Bommelaer, Kummer, Orlov, Ponder, Reed, \& Yakushev, 2013, pp. 185-206).

\section{Acknowledgments}

Research is conducted with the financial aid of the grant of the President of the Russian Federation MK-4283.2015.6.

\section{References}

Australia-Oceania: Tokelau (territory of New Zealand). (2014). The World Factbook. Central Intelligence Agency.

Bachilo, I. (2000). Ubiquitous access to information and the Internet. Information Society, 4, 42-44.

Baseley, W. B., Bommelaer, C., Vasilyev, V., Weber, R., Bommelaer, C., Kummer, M., Orlov, V., Ponder, J., Reed, W., \& Yakushev, M. (2013). International Information Security and Global Internet Governance: a View from Geneva in the Eyes of Russian and International Experts. Security Index, 1(104), 185-206.

Chesnokov, N. (2013). Legal principles of information security in the modern world. Pravovaya Iniciativa, 4, 14. 
Internet. Press releases. (2014). Levada Center. http://www.levada.ru/30-06-2014/ispolzovanie-interneta

Internet in Russia: proliferation trends. Spring 2014. (2014). Public Opinion Foundation. Retrieved from http://runet.fom.ru/Proniknovenie-interneta/11567

Kasenova, M. (2013). Internet assigned numbers authority (IANA) in Internet governance cross-border mechanism. Eurasian Law Journal, 2(57), 63-67.

Korsakov, G. (2012). The information weapons of the superpower. Pathways to peace and security, 1(42), 34-59).

Purposes of the .RU domain use. (2014). Coordination Center for TLD RU. Retrieved from $\mathrm{http}: / /$ statdom.ru/tld/ru/report/sitesusage/\#26

Purposes of the .SU domain use. (2014). Coordination Center for TLD RU. Retrieved from $\mathrm{http}: / /$ statdom.ru/tld/su/report/sitesusage/\#26

Purposes of the .PФ domain use. (2014). Coordination Center for TLD RU. Retrieved from http://statdom.ru/tld/pф/report/sitesusage/\#26

Register of telecommunications licenses. (2015). The Federal Service for Supervision of Communications, Information Technology and Mass Media. Information from the official website http://rkn.gov.ru/communication/register/license/

Russian domain name market: statistics, history, trends. (2014). Russian Network Information Center (RU CENTER). Retrieved from http://stat.nic.ru

The Annual Report. (2014). International Institute of Informatization and Public Administration named in the honor of P. A. Stolypin.

The Domain Name Industry Brief Volume 11 - Issue 1 - April 2014. (2014). VeriSign, Inc. Retrieved from https://www.verisigninc.com/assets/domain-name-report-april2014.pdf

The Domain Name Industry Brief Volume 11 - Issue 3 - December 2014. (2014). VeriSign, Inc. Retrieved from http://www.verisigninc.com/assets/domain-name-report-december2014.pdf

TLDs Alpha By Domain List. (2015). Internet Assigned Address Authority. Retrieved from http://data.iana.org/TLD/tlds-alpha-by-domain.txt

Volkova, N. V. (2013). Some questions of the UN activities in the field of cultural rights protection. Pravovaya Iniciativa, 5, 4 .

\section{Copyrights}

Copyright for this article is retained by the author(s), with first publication rights granted to the journal.

This is an open-access article distributed under the terms and conditions of the Creative Commons Attribution license (http://creativecommons.org/licenses/by/3.0/). 